University of Nebraska - Lincoln

DigitalCommons@University of Nebraska - Lincoln

Public Health Resources

Public Health Resources

2004

Does Breastfeeding Protect Against Pediatric Overweight? Analysis of Longitudinal Data From the Centers for Disease Control and Prevention Pediatric Nutrition Surveillance System

Laurence M. Grummer-Strawn

Centers for Disease Control and Prevention, Atlanta, Georgia, lgrummer-strawn@cdc.gov

Zuguo Mei

Centers for Disease Control and Prevention, Atlanta, Georgia

Follow this and additional works at: http://digitalcommons.unl.edu/publichealthresources

Grummer-Strawn, Laurence M. and Mei, Zuguo, "Does Breastfeeding Protect Against Pediatric Overweight? Analysis of Longitudinal Data From the Centers for Disease Control and Prevention Pediatric Nutrition Surveillance System" (2004). Public Health Resources. 437.

http://digitalcommons.unl.edu/publichealthresources/437

This Article is brought to you for free and open access by the Public Health Resources at DigitalCommons@University of Nebraska - Lincoln. It has been accepted for inclusion in Public Health Resources by an authorized administrator of DigitalCommons@University of Nebraska - Lincoln. 


\title{
Does Breastfeeding Protect Against Pediatric Overweight? Analysis of Longitudinal Data From the Centers for Disease Control and Prevention Pediatric Nutrition Surveillance System
}

\author{
Laurence M. Grummer-Strawn, PhD, and Zuguo Mei, MD
}

\begin{abstract}
Objective. To examine whether increasing duration of breastfeeding is associated with a lower risk of overweight in a low-income population of 4-yearolds in the United States.

Methods. Visit data were linked to determine prospectively the duration of breastfeeding (up to 2 years of age) and weight status at 4 years of age. Overweight among 4-year-old children was defined as a body mass index (BMI)-for-age at or above the 95 th percentile based on the 2000 Centers for Disease Control and Prevention growth charts. Logistic regression was performed, controlling for gender, race/ethnicity, and birth weight. In a subset of states, links to maternal pregnancy records also permitted regression analysis controlling for mother's age, education, prepregnancy BMI, weight gain during pregnancy, and postpartum smoking. Data from the Pediatric Nutrition Surveillance System, which extracts breastfeeding, height, and weight data from child visits to public health programs, were analyzed. In 7 states, data were linked to Pregnancy Nutrition Surveillance System data. A total of 177304 children up to 60 months of age were included in our final pediatric-only analysis, and 12587 were included in the pregnancy-pediatric linked analysis.

Results. The duration of breastfeeding showed a dose-response, protective relationship with the risk of overweight only among non-Hispanic whites; no significant association was found among non-Hispanic blacks or Hispanics. Among non-Hispanic whites, the adjusted odds ratio of overweight by breastfeeding for 6 to 12 months versus never breastfeeding was 0.70 (95\% confidence interval: $0.50-0.99)$ and for $>12$ months versus never was 0.49 (95\% confidence interval: $0.25-0.95)$. Breastfeeding for any duration was also protective against underweight (BMI-for-age below the 5th percentile).

Conclusion. Prolonged breastfeeding is associated with a reduced risk of overweight among non-Hispanic white children. Breastfeeding longer than 6 months provides health benefits to children well beyond the period of breastfeeding. Pediatrics 2004;113:e81-e86. URL: http: //www.pediatrics.org/cgi/content/full/113/2/e81; breastfeeding, overweight, obesity, longitudinal, preschool children, body mass index.
\end{abstract}

From the Maternal and Child Nutrition Branch, Division of Nutrition and Physical Activity, National Center for Chronic Disease Prevention and Health Promotion, Centers for Disease Control and Prevention, Atlanta, Georgia.

Received for publication Jul 1, 2002; accepted Oct 16, 2003.

Reprint requests to (L.M.G.-S.), Centers for Disease Control and Prevention, Mailstop K-25, 4770 Buford Hwy, Atlanta, GA 30341-3724. E-mail: lgrummer-strawn@cdc.gov

PEDIATRICS (ISSN 0031 4005). Copyright (C) 2004 by the American Academy of Pediatrics.
ABBREVIATIONS. BMI, body mass index; CDC, Centers for Disease Control and Prevention.

$\mathrm{T}$ The increasing prevalence of overweight among preschool-age children in the United States has been described as an epidemic. ${ }^{1,2}$ Overweight children are at increased risk of being overweight adults. ${ }^{3,4}$ In addition, children who are overweight already show related signs of morbidity, including elevated blood pressure, cholesterol, triglyceride, and insulin levels.5,6 Thus, prevention of pediatric overweight is important for the long-term prevention of chronic disease.

Evidence in the literature has been contradictory regarding whether breastfeeding is associated with a reduction in the risk of overweight. ${ }^{7}$ A number of authors have found no significant correlation between breastfeeding and various measures in children of mean adiposity, ${ }^{8-10}$ fatness, ${ }^{11}$ or overweight. ${ }^{12-14}$ Agras et al ${ }^{15}$ actually found a higher mean body mass index (BMI) for children who were breastfed the longest durations. Conversely, many researchers have observed a greater risk of overweight in children and adolescents who had not been breastfed compared with those who had ${ }^{16,17}$ or who were breastfed a shorter rather than longer duration. ${ }^{18-25}$ On the basis of a review of 11 studies, Dewey ${ }^{26}$ concluded that "the evidence to date suggests that breastfeeding reduces the risk of child overweight to a moderate extent."

Many of these studies suffered from small sample sizes-especially for breastfeeding durations longer than 6 months-and were underpowered to detect substantively important effects. Also, several of the studies used mean BMI or mean skinfold as an indicator of adiposity. Breastfeeding has been shown to be protective against undernutrition. ${ }^{27,28}$ If breastfeeding protects against underweight as well as overweight, then one would not expect to see an effect on the central tendency of adiposity but only on the extremes. Nearly all of the studies to date that have shown a protective relationship between breastfeeding and overweight were conducted in predominantly white, non-Hispanic populations. Infant feeding patterns in the United States are known to differ dramatically by race and ethnicity. ${ }^{29}$ We examined whether an increasing duration of breastfeeding is associated with a lower risk of overweight among a low-income population of 4-year-olds. Advantages 
of this study include its large sample size, its examination of breastfeeding beyond 12 months of age, and its stratification by racial/ethnic group.

\section{METHODS}

The data for this analysis were drawn from the Centers for Disease Control and Prevention (CDC) Pediatric Nutrition Surveillance System. ${ }^{30}$ This system aggregates data on growth and anemia from low-income children who attend public health clinics across the United States. Data are derived from the Special Supplemental Nutrition Program for Women, Infants, and Children and the Maternal and Child Health Block Grant. Children are seen at a clinic an average of twice a year and have their height and weight measured each time. For children under the age of 2 years, data are also collected on whether the child was ever breastfed and, if so, for how long.

Records for children who are enrolled in these programs were linked by a data processing team based on child identifier and date of birth to create a longitudinal series of heights and weights for each child. Individual identifiers were stripped from the data files before transmission to the researchers. For this analysis, we included only children who had at least 1 visit for each single year of age up to age 5, to guarantee that all of the records with the same identification did in fact come from the same child. We included children who were born between 1988 and 1992 and thus used records for 1988-1997. A total of 246371 children were examined. We excluded all children for whom breastfeeding duration was not assessed $(n=58009)$ or for whom the reported duration of breastfeeding was inconsistent from one visit to the next $(n=10315)$. We also excluded children who did not have data on height, weight, gender, race/ethnicity, and birth weight $(n=743)$. A total of 177304 children were included in our analysis.

In a subset of 7 states, we also had access to maternal pregnancy records from the CDC Pregnancy Nutrition Surveillance System. This system collects data on risk factors during pregnancy in the same public health programs previously described. Data processors linked pregnancy and pediatric records using child identifier and date of birth. The mother's age, educational attainment, selfreported prepregnancy weight, height as measured at the first prenatal visit, weight gain during pregnancy, and postpartum smoking were attached to the child's records. The mother's prepregnancy BMI $\left(\mathrm{kg} / \mathrm{m}^{2}\right)$ was computed. Pregnancy weight gain was categorized as less than ideal, ideal, and greater than ideal as recommended by the Institute of Medicine. ${ }^{31}$ Smoking was categorized as none, $<10$ cigarettes per day, and $\geq 10$ cigarettes per day. A total of 12587 mother-child pairs were included in this subanalysis.

Breastfeeding duration was categorized into 6 categories: never, $<1$ month, 1 to 2 months, 3 to 5 months, 6 to 11 months, and $\geq 12$ months. No information was collected in this system on the introduction of solid foods or other milks. Overweight among 4-year-old children was defined as having a BMI-for-age above the 95th percentile based on the 2000 CDC growth reference. ${ }^{32,33}$ When a child had $>1$ clinic visit while 4 years old, only 1 visit was selected at random. Because we were also concerned about whether breastfeeding affects only overweight or actually shifts the entire BMI distribution, we also looked at underweight, defined as a BMI-for-age below the 5th percentile.

We conducted a logistic regression on the odds of being overweight by the 6 breastfeeding categories. In this analysis, we controlled for gender, race/ethnicity, and birth weight. In the subset of states in which linkage to maternal records was possible, we also controlled for mother's age, educational attainment, prepregnancy BMI, weight gain during pregnancy, and postpartum smoking. Finally, we tested for interactions between breastfeeding duration and each of the covariates.

\section{RESULTS}

The population studied had a high percentage of overweight children (13.3\%) and a high proportion of non-Hispanic blacks (29.0\%; Table 1). The percentage of low birth weight was slightly higher than that found nationally, but this was to be expected because our sample included only low-income children
( $<185 \%$ of poverty). Fewer than $30 \%$ of the children were ever breastfed, and only $6.1 \%$ were breastfed for $>6$ months. Among the $2.5 \%$ of children who were excluded because of missing or inconsistent breastfeeding duration, the prevalence of overweight was slightly higher (14.4\% vs $13.3 \%$ ). These excluded children were more likely to be from an "other" racial/ethnic group (14.0\% vs 5.0\%). The subsample of children who were linked to maternal data in the 7 states was more likely to be Hispanic and had a higher rate of breastfeeding and the mothers were generally poorly educated $(43.6 \%$ had not completed high school) and had a high prevalence of overweight before their pregnancy $(41.7 \%$ with $\mathrm{BMI}$ $>25$ ).

The rate of overweight at 4 years of age was highest among children who were never breastfed or who were breastfed for $<1$ month; furthermore, overweight decreased with increasing breastfeeding duration (Table 2). The rate of underweight was highest among children who were never breastfed. Thus, children who were breastfed are less likely to be either overweight or underweight. The mean BMI of children was virtually identical across breastfeeding categories, but the standard deviation of BMI monotonically decreased with increasing breastfeeding duration.

Results of the logistic regression analysis confirmed these results (Table 3). In fact, the odds ratios were slightly stronger after we controlled for gender, race/ethnicity, and birth weight. When we also controlled for mother's age, education, prepregnancy $\mathrm{BMI}$, weight gain during pregnancy, and postpartum smoking, the effects of breastfeeding for $<1$ year were considerably diminished (Table 4), but prolonged breastfeeding (at least 12 months) was associated with a substantial (but nonsignificant) reduction in risk of pediatric overweight.

In testing for interactions between breastfeeding and the other covariates in predicting pediatric overweight, only the interaction between race/ethnicity and breastfeeding duration was statistically significant. A dose-response effect of longer breastfeeding was observed among non-Hispanic whites but not among non-Hispanic blacks or Hispanics (Table 4). The sample size in the "other" racial/ethnic group was too small to show statistically significant effects, but the odds ratios were similar to those for nonHispanic whites.

\section{DISCUSSION}

Our study documented lower rates of overweight among children who were breastfed for longer durations. This finding is consistent with several previous articles that concluded that breastfeeding is protective against pediatric overweight. ${ }^{19-25}$ Each of those reports describes primarily non-Hispanic white populations. In our study, breastfeeding was protective among non-Hispanic whites but not other racial/ethnic groups.

Few of the previous studies examined prolonged breastfeeding, that is, breastfeeding for $>1$ year. The 2 studies that did report separately for those who were breastfed for at least 1 year found relatively 
TABLE 1. Prevalence of Sample Characteristics, Pediatric and Pregnancy Nutrition Surveillance System Linked Cohort, 1988-1997

\begin{tabular}{|c|c|c|}
\hline & $\begin{array}{l}\text { Pediatric Data Only } \\
\qquad(N=177304)\end{array}$ & $\begin{array}{c}\text { Pregnancy / Pediatric } \\
\text { Linked Data } \\
(N=12587)\end{array}$ \\
\hline \multicolumn{3}{|l|}{ BMI-for-age at $4 \mathrm{y}$} \\
\hline$<5$ th percentile & 4.7 & 3.4 \\
\hline 5th-95th percentile & 82.0 & 80.3 \\
\hline$>95$ th percentile & 13.3 & 16.3 \\
\hline \multicolumn{3}{|l|}{ Breastfeeding duration } \\
\hline Never breastfed & 71.1 & 56.3 \\
\hline$<1 \mathrm{mo}$ & 9.9 & 16.1 \\
\hline $1-2.9 \mathrm{mo}$ & 8.1 & 9.1 \\
\hline $3-5.9 \mathrm{mo}$ & 4.8 & 8.8 \\
\hline 6-11.9 mo & 4.0 & 8.7 \\
\hline$\geq 12 \mathrm{mo}$ & 2.1 & 1.0 \\
\hline \multicolumn{3}{|l|}{ Gender } \\
\hline Male & 50.6 & 49.7 \\
\hline Female & 49.4 & 50.3 \\
\hline \multicolumn{3}{|l|}{ Race/ethnicity } \\
\hline White, non-Hispanic & 52.1 & 42.1 \\
\hline Black, non-Hispanic & 29.0 & 23.6 \\
\hline Hispanic & 13.9 & 26.3 \\
\hline Other & 5.0 & 8.0 \\
\hline \multicolumn{3}{|l|}{ Birth weight } \\
\hline$<2500 \mathrm{~g}$ & 10.5 & 8.6 \\
\hline $2500-3999 \mathrm{~g}$ & 81.1 & 82.7 \\
\hline$\geq 4000 \mathrm{~g}$ & 8.4 & 8.7 \\
\hline \multicolumn{3}{|l|}{ Mother's age } \\
\hline$<20 y$ & - & 22.3 \\
\hline $20-29 y$ & - & 53.6 \\
\hline$\geq 30 y$ & - & 24.1 \\
\hline \multicolumn{3}{|l|}{ Mother's education } \\
\hline$<$ High school & - & 43.6 \\
\hline Completed high school & - & 42.0 \\
\hline$>$ High school & - & 14.4 \\
\hline \multicolumn{3}{|l|}{ Mother's prepregnancy BMI } \\
\hline$<18.5$ & - & 7.0 \\
\hline $18.5-24.9$ & - & 51.1 \\
\hline $25-29.9$ & - & 23.6 \\
\hline$\geq 30$ & - & 18.1 \\
\hline \multicolumn{3}{|c|}{ Mother's postpartum smoking status } \\
\hline Did not smoke & - & 78.1 \\
\hline$<10$ cigarettes/day & - & 8.1 \\
\hline$\geq 10$ cigarettes/day & - & 13.8 \\
\hline \multicolumn{3}{|l|}{ Weight gain during pregnancy } \\
\hline Less than recommended & - & 29.7 \\
\hline Recommended & - & 42.3 \\
\hline More than recommended & - & 28.0 \\
\hline
\end{tabular}

TABLE 2. Prevalence of Overweight and Underweight and Mean BMI at 4 Years of Age, by Breastfeeding Duration, Pediatric Nutrition Surveillance System Cohort, 1988-1997

\begin{tabular}{lrcccc}
\hline $\begin{array}{c}\text { Breastfeeding } \\
\text { Duration }\end{array}$ & $n$ & $\begin{array}{c}\text { Overweight, } \\
\%\end{array}$ & $\begin{array}{c}\text { Underweight, } \\
\%\end{array}$ & \multicolumn{2}{c}{ BMI } \\
\cline { 5 - 6 } & & & & Mean & $\begin{array}{c}\text { Standard } \\
\text { Deviation }\end{array}$ \\
\hline Never breastfed & 126018 & 13.6 & 5.0 & 16.3 & 2.03 \\
$<1$ mo & 17466 & 13.7 & 3.9 & 16.3 & 1.93 \\
$1-2.9$ mo & 14388 & 12.8 & 3.9 & 16.3 & 1.93 \\
$3-5.9$ mo & 8500 & 12.4 & 4.0 & 16.3 & 1.87 \\
$6-11.9$ mo & 7169 & 11.3 & 3.5 & 16.2 & 1.81 \\
$\geq 12$ mo & 3763 & 11.0 & 4.5 & 16.1 & 1.81 \\
\hline
\end{tabular}

large effects. Von Kries et al ${ }^{19}$ found a $57 \%$ reduction in the adjusted odds of being overweight at 5 or 6 years of age when contrasting those who were breastfed for at least 12 months with those who were never breastfed. Liese et $\mathrm{al}^{23}$ found even stronger effects contrasting $>1$ year of breastfeeding with those who were not breastfed, a $71 \%$ reduction in odds. Among white children, we found a 51\% reduction for a similar comparison.
We did not find any protection against overweight among those who were breastfed for short durations $(<3$ months). Although never significant, there is even some suggestion of slightly higher rates of overweight among those who were breastfed for only a few months compared with those who were never breastfed, particularly among non-Hispanic blacks. Gillman et $\mathrm{al}^{20}$ similarly documented slightly higher rates of overweight among those who were breastfed 
TABLE 3. Crude and Adjusted Odds Ratios of Association Between Breastfeeding Duration and Overweight in Children Aged 4 Years

\begin{tabular}{|c|c|c|c|c|}
\hline \multirow[t]{2}{*}{$\begin{array}{l}\text { Breastfeeding } \\
\text { Duration }\end{array}$} & \multicolumn{2}{|c|}{ Crude Association } & \multicolumn{2}{|c|}{$\begin{array}{l}\text { Adjusted for Child's Gender, } \\
\text { Race/Ethnicity, and Birth Weight }\end{array}$} \\
\hline & Odds Ratio & $\begin{array}{l}\text { 95\% Confidence } \\
\text { Interval }\end{array}$ & $\begin{array}{l}\text { Adjusted } \\
\text { Odds Ratio }\end{array}$ & $\begin{array}{l}\text { 95\% Confidence } \\
\text { Interval }\end{array}$ \\
\hline Never breastfed & 1.00 & - & 1.00 & - \\
\hline$<1 \mathrm{mo}$ & 1.01 & $0.97-1.06$ & 0.98 & $0.94-1.03$ \\
\hline $1-2.9 \mathrm{mo}$ & 0.94 & $0.89-0.99$ & 0.88 & $0.83-0.93$ \\
\hline 3-5.9 mo & 0.90 & $0.84-0.96$ & 0.81 & $0.76-0.87$ \\
\hline 6-11.9 mo & 0.82 & $0.76-0.88$ & 0.73 & $0.68-0.79$ \\
\hline$\geq 12 \mathrm{mo}$ & 0.79 & $0.71-0.88$ & 0.72 & $0.65-0.80$ \\
\hline
\end{tabular}

TABLE 4. Adjusted* Odds Ratios of the Association Between Breastfeeding and Overweight in Children Aged 4 Years, by Race/Ethnicity

\begin{tabular}{|c|c|c|c|c|}
\hline $\begin{array}{c}\text { Race/Ethnicity and } \\
\text { Breastfeeding Duration }\end{array}$ & $n$ & $\begin{array}{c}\text { Overweight } \\
(\%)\end{array}$ & Odds Ratio & $\begin{array}{l}\text { 95\% Confidence } \\
\text { Interval }\end{array}$ \\
\hline \multicolumn{5}{|l|}{ All races } \\
\hline Never breastfed & 7084 & 16.1 & 1.00 & - \\
\hline$<1 \mathrm{mo}$ & 1706 & 18.6 & 1.12 & $0.97-1.30$ \\
\hline $1-2.9 \mathrm{mo}$ & 1451 & 17.9 & 1.06 & $0.91-1.24$ \\
\hline 3-5.9 mo & 1064 & 16.3 & 0.91 & 0.75-1.09 \\
\hline 6-11.9 mo & 989 & 15.9 & 0.93 & $0.76-1.12$ \\
\hline$\geq 12 \mathrm{mo}$ & 293 & 13.7 & 0.76 & $0.53-1.08$ \\
\hline \multicolumn{5}{|l|}{ White, non-Hispanic } \\
\hline Never breastfed & 3174 & 14.5 & 1.00 & - \\
\hline$<1 \mathrm{mo}$ & 643 & 14.3 & 0.99 & $0.77-1.27$ \\
\hline $1-2.9 \mathrm{mo}$ & 510 & 14.9 & 1.14 & $0.87-1.50$ \\
\hline 3-5.9 mo & 377 & 10.6 & 0.73 & $0.51-1.05$ \\
\hline 6-11.9 mo & 448 & 9.8 & 0.70 & $0.50-0.99$ \\
\hline$\geq 12 \mathrm{mo}$ & 150 & 6.7 & 0.49 & $0.25-0.95$ \\
\hline \multicolumn{5}{|l|}{ Black, non-Hispanic } \\
\hline Never breastfed & 1659 & 13.3 & 1.00 & - \\
\hline$<1 \mathrm{mo}$ & 456 & 18.0 & 1.32 & $0.98-1.76$ \\
\hline $1-2.9 \mathrm{mo}$ & 332 & 16.6 & 1.31 & $0.93-1.83$ \\
\hline 3-5.9 mo & 261 & 17.2 & 1.27 & $0.88-1.83$ \\
\hline 6-11.9 mo & 203 & 19.2 & 1.36 & $0.91-2.01$ \\
\hline$\geq 12 \mathrm{mo}$ & 56 & 14.3 & 0.87 & $0.40-1.89$ \\
\hline \multicolumn{5}{|l|}{ Hispanic } \\
\hline Never breastfed & 1478 & 22.5 & 1.00 & - \\
\hline$<1 \mathrm{mo}$ & 520 & 24.6 & 1.12 & $0.88-1.43$ \\
\hline $1-2.9 \mathrm{mo}$ & 536 & 21.5 & 0.90 & $0.70-1.16$ \\
\hline 3-5.9 mo & 394 & 21.6 & 0.89 & $0.67-1.18$ \\
\hline 6-11.9 mo & 315 & 22.9 & 0.98 & $0.72-1.32$ \\
\hline$\geq 12 \mathrm{mo}$ & 70 & 28.6 & 1.11 & $0.64-1.92$ \\
\hline \multicolumn{5}{|l|}{ Other } \\
\hline Never breastfed & 773 & 16.2 & 1.00 & - \\
\hline$<1 \mathrm{mo}$ & 87 & 17.2 & 1.01 & $0.55-1.87$ \\
\hline $1-2.9 \mathrm{mo}$ & 73 & 17.8 & 1.03 & $0.53-1.98$ \\
\hline 3-5.9 mo & 32 & 3.4 & 0.46 & $0.13-1.58$ \\
\hline 6-11.9 mo & 23 & 8.7 & 0.52 & $0.12-2.31$ \\
\hline$\geq 12 \mathrm{mo}$ & 17 & 11.8 & 0.46 & $0.10-2.18$ \\
\hline
\end{tabular}

* Adjusted for child's gender, race/ethnicity, and birth weight and mother's age, education, prepregnancy BMI, weight gain during pregnancy, and postpartum smoking.

for $<3$ months compared with those who were never breastfed. Apparently, the protective effects of breastfeeding are gained only when breastfeeding continues for at least 3 months.

Our study also showed that longer breastfeeding is not associated with a decrease in mean BMI but rather with a decrease in the standard deviation of the BMI, leading to simultaneously lower rates of underweight and overweight. Thus, our results are also consistent with previous studies that demonstrated no association between breastfeeding and various measures of central tendency of weight or adiposity.${ }^{8-10}$ Breastfeeding seems to protect against overweight not by uniformly reducing BMI in all children but by reducing the variability in BMI.

A number of strengths distinguish our study. It is one of the largest studies conducted to date examining breastfeeding and overweight. Unlike many previous studies, it controls for maternal BMI and a number of other factors known to be associated with both breastfeeding and overweight. All participants were low-income and thus relatively homogeneous in socioeconomic status. It stratifies the analyses by race/ethnicity and demonstrates differential effects by racial/ethnic group.

However, there are a few limitations as well. 
Women who breastfeed for longer durations could be different from women who do not breastfeed in ways not measured by the variables that we considered. As Gillman ${ }^{34}$ pointed out, "The most important question about these studies is whether residual confounding could explain the results" (p. 749). By controlling for the child's gender, race/ethnicity, and birth weight, and for the mother's age, education, prepregnancy BMI, weight gain during pregnancy, and postpartum smoking, we attempted to minimize the effect of confounding variables, but it is possible that factors indirectly related to breastfeeding and overweight are responsible for the association. Perhaps most important, we could not control for nutrition and physical activity behaviors in the children as they grew older. Furthermore, the sample was not representative of all low-income children in the United States but only of those enrolled in public health programs. Such children may have characteristics that set them apart from nonparticipants. We did not have data on the exclusivity of breastfeeding or on other aspects of infant feeding. Also, we were unable to examine effects of breastfeeding after the age of 4 years, for which Dewey ${ }^{26}$ pointed out that effects seem to be even stronger.

The link between long-term breastfeeding and lower rates of overweight could operate through several possible biological mechanisms. Birch and Fisher ${ }^{35}$ showed that children who were breastfed are better able to adjust intake at a meal in response to a high calorie preload; thus, breastfed children may learn to self-regulate caloric intake better than nonbreastfed infants do. Also, breastfed and formula-fed infants have a different hormonal response to feeding: formula feeding provokes a greater insulin response, possibly resulting in earlier fat deposition. ${ }^{36,37}$ Another possibility is that the higher protein intake in formula-fed infants has a programming effect on glucose metabolism. ${ }^{38}$ Finally, breastfed infants adapt more readily to new foods such as vegetables, thus influencing the subsequent caloric density of their diet.

That effects were found consistently only in nonHispanic whites suggests that the association may be mediated by behavioral factors that differ across racial/ethnic groups. For example, Hispanic children are at nearly twice the risk of becoming overweight than are non-Hispanic whites, probably because of different dietary and physical activity patterns. Prolonged breastfeeding may be insufficient to overcome these powerful lifestyle issues. Furthermore, the exclusivity of breastfeeding or the age of introduction of solid foods may differ by ethnic group, such that the effects of breastfeeding are weaker in black or Hispanic children. We could not characterize the intensity of breastfeeding, as no data on supplementation with other milks or solid foods were available in this data set. It is also possible that infant formula is used differently in the different ethnic groups. For example, if whites are more insistent that their infants finish off a predetermined quantity of formula, then this may inhibit a formula-fed infant's ability to self-regulate intake. These hypotheses clearly will require additional examination.
The multiple benefits of breastfeeding are well documented in the United States. ${ }^{39,40}$ Much of the current evidence on the health effects of breastfeeding has been concentrated on shorter durations of breastfeeding, however. The importance of longterm breastfeeding (longer than 12 months) has not been documented extensively in developed countries. This study highlights 1 consequence of prolonged breastfeeding and reinforces the rationale for recommendations to breastfeed an infant for at least a full year.

\section{REFERENCES}

1. Ogden CL, Flegal KM, Carroll MD, Johnson CL. Prevalence and trends in overweight among US children and adolescents, 1999-2000. JAMA. 2002;288:1728-1732

2. Mei Z, Scanlon KS, Grummer-Strawn LM, Freedman DS, Yip R, Trowbridge FL. Increasing prevalence of overweight among US low-income preschool children: the Centers for Disease Control and Prevention Pediatric Nutrition Surveillance, 1983 to 1995. Pediatrics. 1998;101(1). Available at: www.pediatrics.org/cgi/content/full/101/1/e12

3. Whitaker RC, Wright JA, Pepes MS, Seidel KD, Dietz WH. Predicting obesity in young adulthood and parental obesity. N Engl J Med. 1997; 337:869-873

4. Guo SS, Roche AF, Chumlea WC, Gardner JD, Siervogel RM. The predictive value of childhood body mass index values for overweight at age 35 y. Am J Clin Nutr. 1994;59:810-819

5. Freedman DS, Dietz WH, Srinivasan SR, Berenson GS. The relation of overweight to cardiovascular risk factors among children and adolescents: the Bogalusa Heart Study. Pediatrics. 1999;103:1175-1182

6. Becque MD, Katch VL, Rocchini AP, Marks CR, Moorehead C. Coronary risk incidence of obese adolescents: reduction by exercise plus diet intervention. Pediatrics. 1988;81:605-612

7. Butte NF. The role of breastfeeding in obesity. Pediatr Clin North Am. 2001;48:189-198

8. Fomon SJ. Factors influencing food consumption in the human infant. Int J Obes. 1980;4:348-350

9. Baranowski T, Bryan GT, Rassin DK, Harrison JA, Henske JC. Ethnicity, infant-feeding practices, and childhood adiposity. J Dev Behav Pediatr. 1990;11:23-29

10. Zive MM, McKay H, Frank-Spohrer GC, Broyles SL, Nelson JA, Nader PR. Infant-feeding practices and adiposity in 4-y-old Anglo- and Mexican-Americans. Am J Clin Nutr. 1992;55:1104-1108

11. Wolman PG. Feeding practices in infancy and prevalence of obesity in preschool children. J Am Diet Assoc. 1984;84:436-438

12. Hediger ML, Overpeck MD, Kuczmarski RI, Ruan WJ. Association between infant breastfeeding and overweight in young children. JAMA. 2001;285:2453-2460

13. Wadsworth M, Marshall S, Hardy R, Paul A. Breast feeding and obesity: relation may be accounted for by social factors. Br Med J. 1999;319:1576

14. O'Callaghan MJ, Williams GM, Andersen MJ, Bor W, Najman JM. Prediction of obesity in children at 5 years: a cohort study. J Paediatr Child Health. 1997;33:311-316

15. Agras WS, Kramer HC, Berkowitz RI, Hammer LD. Influence of early feeding style on adiposity at 6 years of age. J Pediatr. 1990;1:116:805-809

16. Kramer MS. Do breast-feeding and delayed introduction of solid foods protect against subsequent obesity? J Pediatr. 1981;98:883-887

17. Toschke AM, Vignerova J, Lhotska L, Osancova K, Koletzko B, von Kries R. Overweight and obesity in 6- to 14-year old Czech children in 1991: protective effect of breast-feeding. J Pediatr. 2002;141:764-769

18. Strbák V, Skultyova M, Hromadova M, Randuskova A, Macho L. Late effects of breast-feeding and early weaning: seven-year prospective in study in children. Endocr Regul. 1991;25:53-57

19. Von Kries R, Koletzko B, Sauerwald T, et al. Breast feeding and obesity: cross sectional study. BMJ. 1999;319:147-150

20. Gillman MW, Rifas-Shiman SL, Camargo CA, et al. Risk of overweight among adolescents who are breastfed as infants. JAMA. 2001;285: 2461-2467

21. Armstrong J, Reilly JJ, Child Health Information Team. Breastfeeding and childhood obesity risk. Lancet. 2002;359:2003-2004

22. Bergmann KE, Bergmann RL, von Kries R, et al. Early determinants of childhood overweight and adiposity in a birth cohort study: role of breastfeeding. Int J Obes. 2003;27:162-172

23. Liese AD, Hirsch T, von Mutius E, Keil U, Leupold W, Weiland SK. 
Inverse association of overweight and breast feeding in 9 to 10-y-old children in Germany. Int J Obes. 2001;25:1644-1650

24. Poulton R, Williams S. Breastfeeding and risk of overweight. JAMA. 2001;286:1449-1450

25. Tulldahl J, Pettersson K, Andersson SW, Hulthen L. Mode of infant feeding and achieved growth in adolescence: early feeding patterns in relation to growth and body composition in adolescence. Obes Res. 1999;7:431-437

26. Dewey KG. Is breastfeeding protective against child obesity? J Hum Lact. 2003;19:9-18

27. Kanaaneh H. The relationship of bottle feeding to malnutrition and gastroenteritis in a pre-industrial setting. I Trop Pediatr Environ Child Health. 1972;18:302-306

28. Wray JD, Aguirre A. Protein-calorie malnutrition in Candelaria, Colombia. I. Prevalence: social and demographic causal factors. J Trop Pediatr. $1969 ; 15: 76-98$

29. Li R, Zhao Z, Mokdad A, Barker L, Grummer-Strawn L. Prevalence of breastfeeding in the United States: the 2001 National Immunization Survey. Pediatrics. 2003;111:1198-1201

30. Centers for Disease Control and Prevention. Pediatric Nutrition Surveillance, 1997 Full Report. Atlanta: US Department of Health and Human Services, Centers for Disease Control and Prevention; 1998

31. Institute of Medicine. Nutrition during lactation. Report of the Subcommittee on Nutrition During Lactation, Committee on Nutritional Status During Pregnancy and Lactation. Food and Nutrition Board. Washington, DC: National Academy Press; 1991
32. Kuczmarski RJ, Ogden CL, Grummer-Strawn LM, et al. CDC growth charts: United States. Adv Data. 2000;314:1-27

33. Ogden CL, Kuczmarski RJ, Flegal KM, et al. Centers for Disease Control and Prevention 2000 growth charts for the United States: improvements to the 1977 National Center for Health Statistics version. Pediatrics. 2002;109:45-60

34. Gillman MW. Breast-feeding and obesity. J Pediatr. 2002;141:749-750 (editorial)

35. Birch LL, Fisher JO. Development of eating behaviors among children and adolescents. Pediatrics. 1998;101:539-548

36. Lucas A, Sarson DL, Blackburn AM, Adrian TE, Aynsley-Green A, Bloom SR. Breast vs. bottle: endocrine responses are different with formula feeding. Lancet. 1980;1:1267-1269

37. Lucas A, Boyes S, Bloom SR, Aynsley-Green A. Metabolic and endocrine responses to a milk feed in six-day-old term infants: differences between breast and cow's milk formula feeding. Acta Paediatr Scand. 1981;70:195-200

38. Burns SP, Desai M, Cohen RD, et al. Gluconeogenesis, glucose handling, and structural changes in livers of the adult offspring of rats partially deprived of protein during pregnancy and lactation. J Clin Invest. 1997; 100:1768-1774

39. American Academy of Pediatrics, Work Group on Breast-feeding. Breast-feeding and the use of human milk. Pediatrics. 1997;100: 1035-1039

40. US Department of Health and Human Services. HHS Blueprint for Action on Breastfeeding. Washington, DC: US Department of Health and Human Services, Office on Women's Health; 2000 